\title{
Decision-making Study on Mechanism and Priority of Functional Objective of the Manufacturing System
}

\author{
Wei Xu, Qingshan Zhang, Yue Cao and Haijun Wang \\ Shenyang University of Technology, Shenyang University of Technology, Shenyang \\ University of Technology, Shenyang University of Technology \\ 369252882@qq.com, Zhangq1898@163.com,1104898448@qq.com, \\ 121795985@qq.com
}

\begin{abstract}
The aim of this paper established priority level determines method of manufacturing system functional objective based QFD theory, priority sequence presented and the functional objective priority weights, advised manufacturing system functional objective decisions, provides technology support and application reference for system functional objective decisions.
\end{abstract}

Keywords: Manufacturing system, Functional objective, Quality Function Deployment (QFD), Priority

\section{Introduction}

Manufacturing system faces a lot of problems functional objective decision in the parts of design, reengineering and update. The selection of functional objective related to the implementation and coordination of business operation process, also related to the reengineering of the business industrial processes. Many domestic and foreign scientific researchers have carried out the research and analysis it [1-6]. Meanwhile, as an artificial system, the service oriented manufacturing system has its subjective purpose. People play a leading role in the design and structure of manufacturing systems, but it didn't work on the determination of system function, this means that the determination of the system function does not depend on recognize of the subjectivity or the ideology but originate from the needs and strengths of customers. So, manufacturing companies need to formulate the appropriate strategy to fit the need of customers [7].The openness of internal environment and the external environment enabled the decision of system functional objective to have massive randomness and the uncertainty. Simultaneously, there is conflict among these goals. A big difficult problem is how to obtain the most superior objective selection and combination to have the superiority and make the manufacture system to be more effective.

This paper emphatically analyzes the influence effects from customer demand, the enterprise demand, and the competitive demands to the system functional objective, and uses the expanded QFD model as the frame to solve the policy-making weight problems of manufacture system functional objective. This paper has a strong practical significance in providing the data support for the system functional objective decision-making, consummating system function theory and enterprise competition strategy formulation. 


\section{Evolution and Mechanism of Manufacturing System Functional Objective}

\subsection{The Evolution of Manufacturing System Functional Objective}

Manufacturing industry of 21 stcentury has the following trends [8-14]:

(1) The Constraint of Low carbon economy;

(2) The Pressure of Green environmental protection;

(3) The Strong demand of Technological innovation;

(4) The rising proportion of service in industry value chain ;

(5) The adjustment of industrial structure;

(6) The Diversification and Individualization of the customers' demand.

Not only this caused the determination of manufacture system goal must contain the information of the product customers wanted, but also must have the market competition condition, the competitive advantage orientation and the intensity, the competition strategy, as well as core competitive power cultivation and promotion.

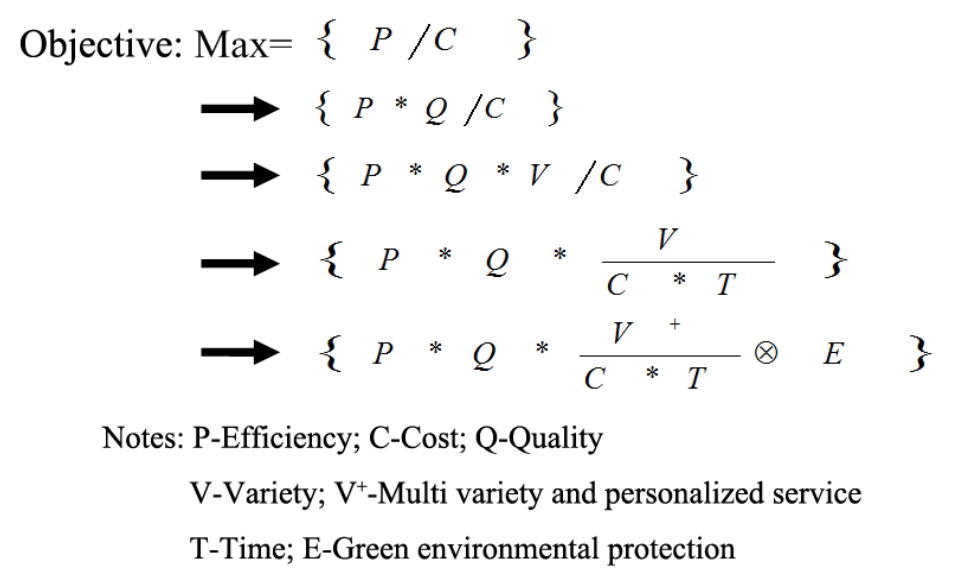

\section{Figure 1. The Evolving Function of the System Functional Objective}

System function should be adapted to this situation and promote enterprise's core competence of their objective selection by this opportunity need continuously updated. As shown in Figure 1, manufacturing system needs to get integrated balance in elements of orientation, quality, time, cost, efficiency, diversification, personalization and customization, green competitive advantages. Ensure the basic needs of customers' need and improve the enterprise's eligibility for competition in the market, carry forward their own features to meet customers' expectations and companies will get the win element sin competitive market [15-16].The former is the basic condition for participation in the competition, the latter is the characteristics to achieve success in the competition of the enterprises, and both complement one another indispensably.

\subsection{The Mechanism of Factor Effects of Manufacturing System Functional Objective}

All systems are running in certain environments, environment will affect the system and the system will exert their influence on the environment. Manufacturing systems exist in specific internal and external environment, external environment includes a competitive environment, a customer' needs environment, internal environment is the environment of enterprise. 
(1) The analysis of mechanism and influence of demand environment to system functional objective decision-making

System dynamics is mainly used to study the feedback process of complex problem. First through the observation and understanding on demand environment, collecting information on customer demand, then according to the customer demand to develop the system functional objective decision, the decision results will promote enterprise competitive advantage, enterprises have a competitive advantage in the competitive market and effect on customer demand or to meet customer demand, so as to form a feedback loop in the system.

There is a link between customer demands and the interaction with the system functional objective. Some demands and improving the system functional objective showed a positive correlation, and some of the demand is no correlation between the objective system, and even some of them for the development of the system has a hindered effect for designed the system functional objective. Using the dynamic principle of the system, we can clearly research the customer demand for intuitive system objectives and effects of competitive advantage, as shown in Figure 2.

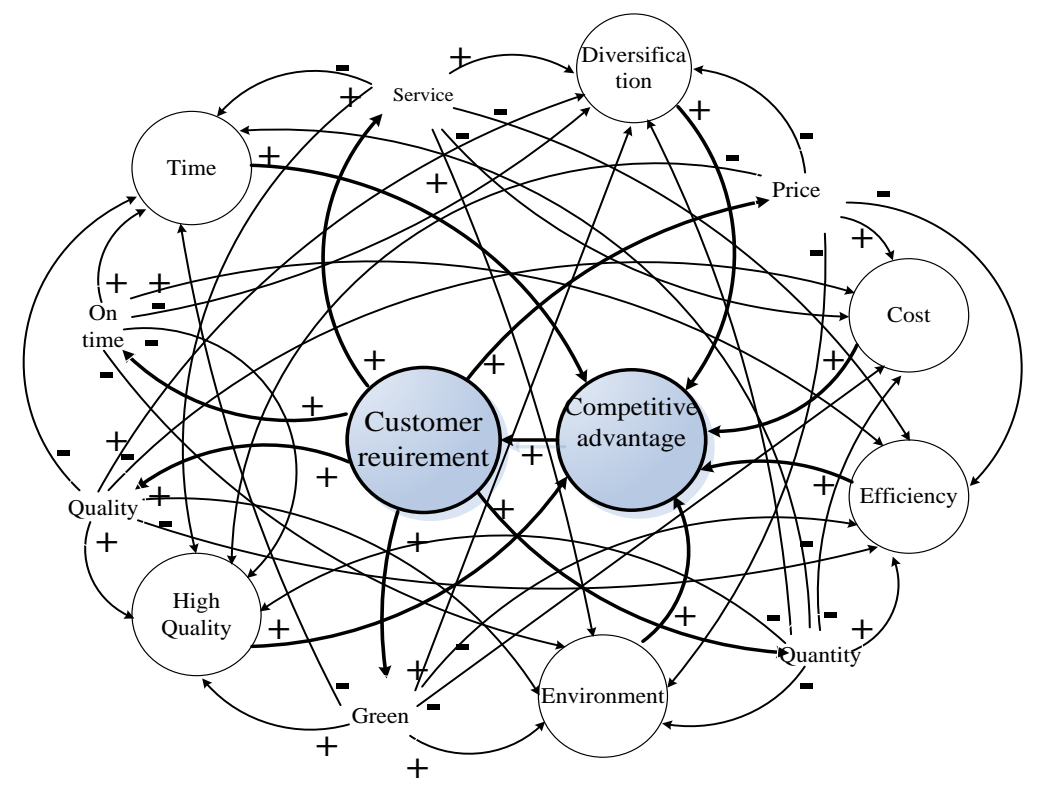

\section{Figure 2. The Function Mechanism Between the Customers Requirements and the System Functional Objective}

(2) The analysis effect and Mechanism of the competitive environment have the influence on decision-making of system functional objective

Companies have different Competitive advantage position, and the manufacturing system functional objectives focused on a different direction. Develop appropriate competitive strategies based on customer expectations of high functional requirements, therefore, determine of competitive strategy is bound to have an impact on each objective system functions. Though distribute different intensities of importance weights of system functional objective, reached optimal overall system. For example, as manufacturing companies, in order to demand the customer's diverse, personalized service requirements, the function of the objective system would need to strengthen the value of the expression "personalized service" function, and this lead to make sacrifices in the "time" and "cost" and other objectives, as shown in Figure 3. 


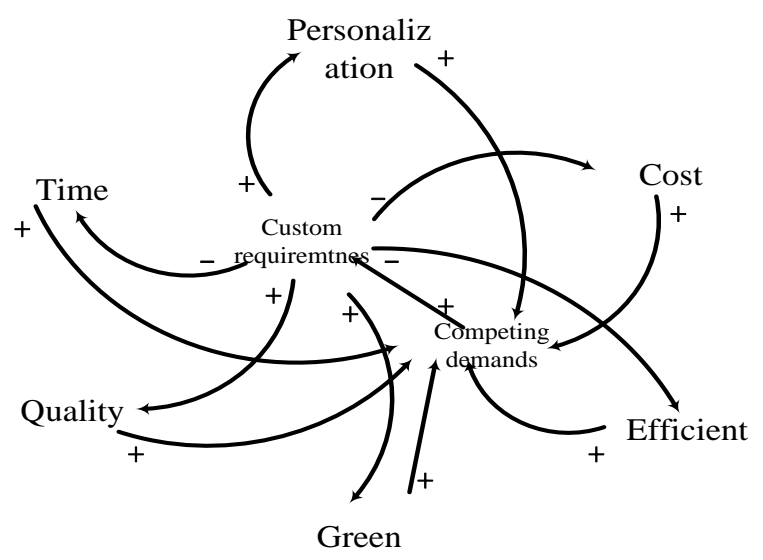

\section{Figure 3. The Function Mechanism of Competitive Strategy on System Functional Objective}

(2) The analysis of function mechanism of system functional objective decision on enterprise environment

For manufacturing enterprises, a objective under its operating conditions to try to make the output and get the maximum profit. Business environment has become a stumbling block to restrict the objective of maximizing benefits, it includes two parts: Part of the business conditions, mainly referring to the existing state of the business, including technology, equipment, supplies, money, staff, etc. Part of the business needs, mainly referring to the power of their own development that is profitable, socially responsible.

Manufacturing system functional objective should meet the two important demands of company production conditions of current companies. Operating profit demands and needs of social responsibility values, namely internal and external responsibilities and namely corporate environmental impact and restrict the formulate of system functional objective, to analysis the advantage, disadvantage and adaptability to the external environment of enterprise in competitive and to further identify the weak links in the business, the key parts and problems, as the basis for the development of functional objective, as shown in Figure 4.

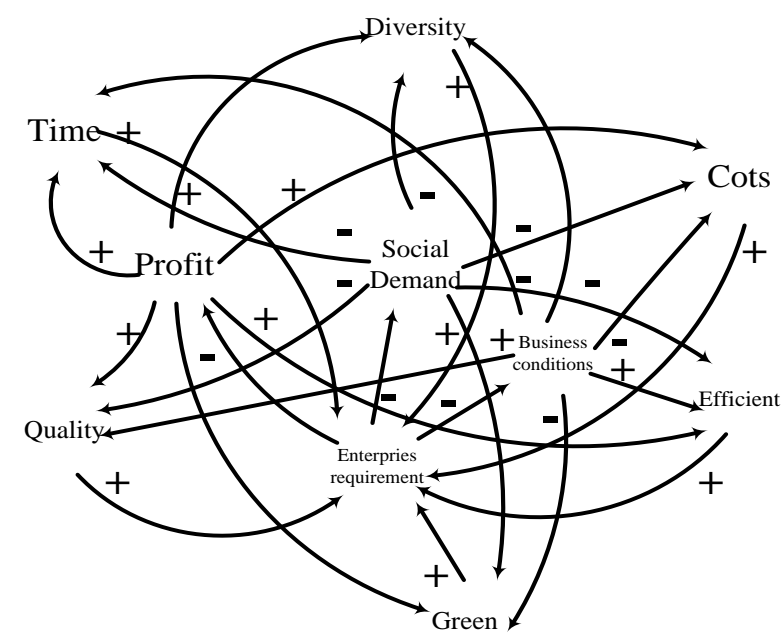

Figure 4. The Function Mechanism of Corporate Environmental System Functional Objective 


\section{Service-Oriented Manufacturing System Function Objective Priority Decisions}

\subsection{Determine the Priority Sequence Thinking}

Through put the value function into prioritization to express the competitive advantage of enterprise, through the various functions gives different weights to realize, it is concluded that the enterprise itself under integrated balance function objective focusing on the direction and intensity, it is crucial for its survival and development. In response to this situation the enterprise using Quality function deployment (Quality function deployment, QFD) to design and manufacture meet or exceed customer expectations of products [11-13], manufacturing system function goal of the three factors as input part, through the principle of QFD system decision-making weight of each objective by function objective priority sequence. The main information contained in this house of quality are: customer demand, competition demand module, and the enterprise demand modules, as shown in Figure 5.

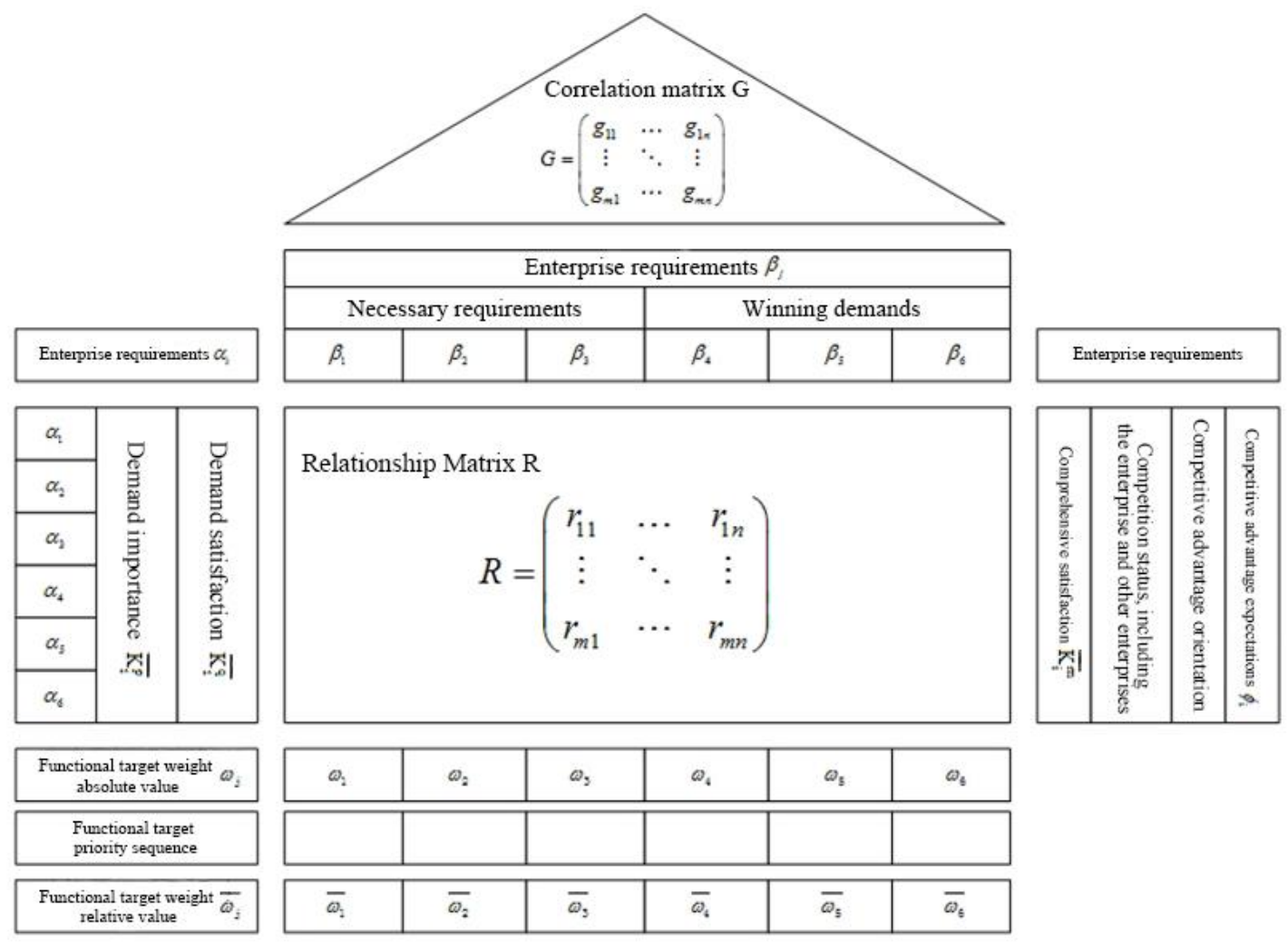

Figure 5. Quality House of Module Construction

\subsection{Priority Decision Model}

(1) Parameter and variable set and instructions

Definition $1, \alpha$ signify as customer demand, denoted by vector $\alpha=\left(\alpha_{1}, \alpha_{2}, \ldots, \alpha_{\mathrm{n}}\right)$, where, $\mathrm{i}=(1,2, \ldots, 6)$, denoted as i kind of customer demands.

Definition 2, $\beta$ signify expressed as a function object, denoted by vector $\beta=\left(\beta_{1}, \beta_{2}, \ldots, \beta_{\mathrm{n}}\right)$, where, $\mathrm{j}=(1,2, \ldots, 6)$, denoted as the $\mathrm{j}$ system functional objective. 
Definition $3, \mathrm{r}_{i j}$ signify relative to the weights of customer requirements $\alpha_{i}$ for the objective function $\beta_{j}, \mathrm{R}=\left[\mathrm{r}_{i j}\right]$ is represented by the customer needs and the function of the objective relative weight matrix.

Definition $4, \overline{\mathrm{K}_{\mathrm{i}}^{\mathrm{p}}}, \mathrm{i}=(1,2, \ldots, 6)$,signify relative importance weights of the $\mathrm{i}$-th customer demands.

Definition $5, \overline{\mathrm{K}_{\mathrm{i}}^{\mathrm{q}}}, \mathrm{i}=(1,2, \mathrm{i}=, \ldots, 6)$, signify satisfaction index of the $\mathrm{i}$-th customer demands.

Definition $6, \overline{\mathrm{K}_{i}^{\mathrm{m}}}, \mathrm{i}=(1,2, \mathrm{i}=, \ldots 6)$, signify comprehensive index of customer demand weights, $\overline{\mathrm{K}_{i}^{\mathrm{m}}}=\sqrt{\overline{\mathrm{K}_{\mathrm{i}}^{\mathrm{p}}} \cdot \overline{\mathrm{K}_{\mathrm{i}}^{\mathrm{q}}}}$.

Definition $7, \eta_{\mathrm{j}}, \mathrm{j}=(1,2, \mathrm{j}=, \ldots 6)$, signify relative other objective objective-effects degree of the $\mathrm{j}$-th functional objective, obtained it by normalized the ideal degree.

Definition $8, \tau_{i}$ signify the enterprise in order to meet the objective satisfaction degree of the i-th customers' demand. The expectation obtained from the company's current competitive than the enterprises to competitive advantage.

Definition $9, \phi_{\mathrm{i}}$ signify the degree of competition advantages of this enterprise relative the other companies on the market.

Definition $10, \omega_{\mathrm{j}}$ signify the final weight of the $\mathrm{j}$-th system function objective of the enterprise value.

(3) Objective priority determination based on the QFD theory

1) Identify customer needs

Analytic Hierarchy Process (AHP) basic principle is pair wise comparison analysis a set objectives which given qualitative description, and analysis the each paired relative importance-degree. According to these quantitative, obtained the respective objective weigh [14].

Specific methods are as follows: (1)The importance of comparing various customer demands: This is a process from qualitative to quantitative, be judged through a quasi-side comparison of the two factors, the importance degree, and assignment in accordance with the ratio of the scale of 1-5 degrees importance, the proportion of marked of Figure 7; (2) Form a judgment matrix; (3) Use root method to calculate the importance weights customer needs $\overline{\mathrm{K}_{i}^{\mathrm{p}}}$,First calculate the absolute importance weights $\mathrm{K}_{\mathrm{i}}^{\mathrm{p}}$, where $\mathrm{i}=1,2, \ldots$, n. Standardization for $\mathrm{K}_{\mathrm{i}}^{\mathrm{p}}, \overline{\mathrm{K}_{\mathrm{i}}^{\mathrm{p}}}=\frac{\mathrm{K}_{\mathrm{i}}^{\mathrm{p}}}{\sum_{i} \mathrm{~K}_{\mathrm{i}}^{\mathrm{p}}}, \mathrm{K}_{\mathrm{i}}^{\mathrm{p}}$ namely customer demand is the weight of importance; (4) Verify the validity of the weights, using the formula $C . R .=C . I / R . I .$, C.I. $=\left(\lambda_{\max }-\mathrm{n}\right) /(\mathrm{n}-1)$, calculated consistency index C.I., R.I. is the average random consistency index , as shown in Table 1.

Table 1. R.I. Value

\begin{tabular}{cllllllllll}
\hline $\begin{array}{c}\text { Judgment } \\
\text { matrix }\end{array}$ & 1 & 2 & 3 & 4 & 5 & 6 & 7 & 8 & 9 \\
\hline R.I. & 0 & 0 & 0.58 & 0.90 & 1.12 & 1.24 & 1.32 & 1.41 & 1.45 \\
\hline
\end{tabular}

Shows C.R. <0.1, consider the consistency of judgment matrix acceptable if C.R.> 0.1, then the data does not have the consistency of the data needs to be corrected until met. 
2) Determination of customer satisfaction

Customer satisfaction determines important condition for quality function deployment success, here are most appropriate for survey methodology is market research combined with Kano model [15]. Unified survey the factors of customer demand to vote and follow the 1-5 satisfaction. Finally, collate satisfaction, through normalized and obtain the weights of demand satisfaction index

3) The determination of enterprise demands

TRIZ is a systems approach, it solve difficult problems based on the basis of objective laws of technical systems evolution. TRIZ provides theoretical guidance for system functional objective development and innovation [16]. And increases the degree is ideal for the most important rule of TRIZ, it showed that technology objective is evolution towards to the direction of increase the ideal degree of increase. The ideal degree is expressed as:

$$
I_{j}=\frac{\sum_{\mathrm{m}} U_{\mathrm{m}}}{\sum_{\mathrm{n}} H_{n}}, \mathrm{~m} \in(0,6], m \in(0,6], j=(1,2, \cdots, 6)
$$

$\mathrm{U}_{\mathrm{m}}$ is the useful result of the system objective. It includes all the useful results which by system functions played role. $\mathrm{H}_{\mathrm{n}}$ refers to the harmful consequences of the system. Ideal state of the system only has valid result, no harmful results. Evaluated the enterprise various demands objective by expert group which consisted of experienced enterprise designers, and determined the relationship between the individual needs of the objective, there are three relationships between the various objectives:

Positive correlation: Signify that the interaction between the two objectives are mutually reinforcing additive effect, assuming that every little change in the amount of the increase in unit variable set $\mathrm{x}$, then the beneficial effect is obtained:

$$
U_{m}=\int_{0}^{1} u_{i}(x) d x, u_{i}(x)=x
$$

Negative relationship: Signify that between the two objectives are superimposed effect of weakening each other, assuming that every change in a small amount, then set the increase in unit variable $\mathrm{z}$, so, the harmful effects obtained was:

$$
\mathrm{H}_{\mathrm{n}}=\int_{0}^{1} h_{i}(z) d z, h_{i}(z)=z ;
$$

Irrelevant: Signify that there is no interaction between the two technology need, the role of values is zero.

According to the formula: $I_{j}=\frac{\sum_{\mathrm{m}} U_{\mathrm{m}}}{\sum_{\mathrm{n}} H_{n}}, \mathrm{m \in}(0,6], m \in(0,6]_{j} j=(1,2 ;, \cdot, 6$, get

Ideal degree vectors I, through normalized and obtain the weight vector of relationship between the system functional objective

4) Determination of competing demands

While conducting customer satisfaction surveys, customers evaluated for competitive conditions of four companies by numbers 1-5. (Including: 1 means customer demand for a particular product for a very unsatisfactory and 5 means customer demand for a particular product for a very satisfied), then obtained competitor assessment data by sort out the investigation file [17]. By the formula:

Competitive strength $\phi_{1}=$ Comprehensive satisfaction $\left(\overline{K_{i}^{m}}\right)$ Objective $\operatorname{satisfaction}\left(\tau_{i}\right)$

Sales consideration $\left(\mathrm{S}_{\mathrm{i}}\right)$

Among these, the three indicators considered $\mathrm{Si}(\mathrm{Si}=1.5, \mathrm{Si}=1.2, \mathrm{Si}=1)$, Where: $\mathrm{Si}$ $=1.5$, it means, if improvement the product or service to meet the of customer demand, then the i-th demand is significant effect on the sales; $\mathrm{Si}=1.2$, it means, if improvement 
the product or service to meet the of customer demand, then the i-th demand is ordinary effect on the sales; $\mathrm{Si}=1$, it means, if improvement the product or service to meet the of customer demand, then the i-th demand is no effect on the sales.

5) Relationships matrix of customer needs and business demand

Relations levels generally use $1-5$, from low to high, from weak to strong (Because between the relationship exists positive and negative, here with + , - sign indicates, but used absolute terms in order to achieve rationality in the calculation)

\section{Example Analysis}

This A company is a manufacturing enterprises, in order to meet customer needs and consider competitive market conditions while combined with its conditions draft the longterm development plan, then select the system functional objective.

(1) Analyze the degree of importance of customer needs according to AHP method; fill in the customer needs respectively in first and second columns in the matrix, and list of mutual importance, Table 2.

Table 2. Customer Demand for Mutual Importance Table

\begin{tabular}{ccccccc}
\hline $\begin{array}{c}\text { Customer } \\
\text { demand for } \\
\text { mutual } \\
\text { importance }\end{array}$ & Price & Quality & Quantity & Delivery & $\begin{array}{c}\text { More } \\
\text { variety, } \\
\text { personalized } \\
\text { service }\end{array}$ & Green \\
\hline Price & 1 & $1 / 2$ & 2 & $1 / 3$ & $1 / 2$ & $1 / 2$ \\
Quality & 2 & 1 & 3 & 4 & 1 & 2 \\
Quantity & $1 / 2$ & $1 / 3$ & 1 & $1 / 2$ & $1 / 4$ & $1 / 3$ \\
$\begin{array}{c}\text { Delivery } \\
\text { More variety, } \\
\text { personalized }\end{array}$ & $1 / 2$ & $1 / 4$ & 2 & 1 & $1 / 3$ & $1 / 2$ \\
service & 3 & 1 & 4 & 3 & 1 & 2 \\
Green & 2 & $1 / 2$ & 3 & 2 & $1 / 2$ & 1 \\
\hline
\end{tabular}

(2) Calculated matrix largest value using Matlab software relative importance $=6.1292$, Using the formula $C . R .=C . I / R . I .$, C.I. $=\left(\lambda_{\max }-\mathrm{n}\right) /(\mathrm{n}-1)$ Then C.R. $=$ 0.0043 , we can see C.R. $<0.1$, considered acceptable the judgment matrix consistency.

(3) According to the customer survey collated customer needs and customer satisfaction weights, weights are shown in Table 3:

Table 3. Customer Demand and Customer Satisfaction Weights Index

\begin{tabular}{ccccccc}
\hline $\begin{array}{c}\text { Customer } \\
\text { demand }\end{array}$ & Price & quality & quantity & Delivery & $\begin{array}{c}\text { More } \\
\text { variety, } \\
\text { personalize } \\
\text { d service }\end{array}$ & Green \\
\hline $\begin{array}{c}\text { Customer } \\
\text { demand }\end{array}$ & 0.116 & 0.266 & 0.061 & 0.104 & 0.285 & 0.168 \\
$\begin{array}{c}\text { Customer } \\
\text { demand }\end{array}$ & 0.176 & 0.176 & 0.235 & 0.235 & 0.119 & 0.059 \\
\hline
\end{tabular}


(4) The table is the relationship between the Autocorrelation business needs of enterprise and these relationships, Figure 6, which can get the correlation matrix of system functional objective relationship:

$$
\mathbf{G}=\left(\begin{array}{cccccc}
1 & \square & \square & \square & \square & \# \\
\square & 1 & \square & \square & \square & \square \\
\square & \square & 1 & \square & \square & \# \\
\square & \# & \square & 1 & \square & \square \\
\square & \# & \square & \square & 1 & \square \\
\# & \square & \# & \square & \square & 1
\end{array}\right)
$$

Weight vector of System functional objective relationships = $0.143,0.107,0.143,0.143,0.143,0.321$ )

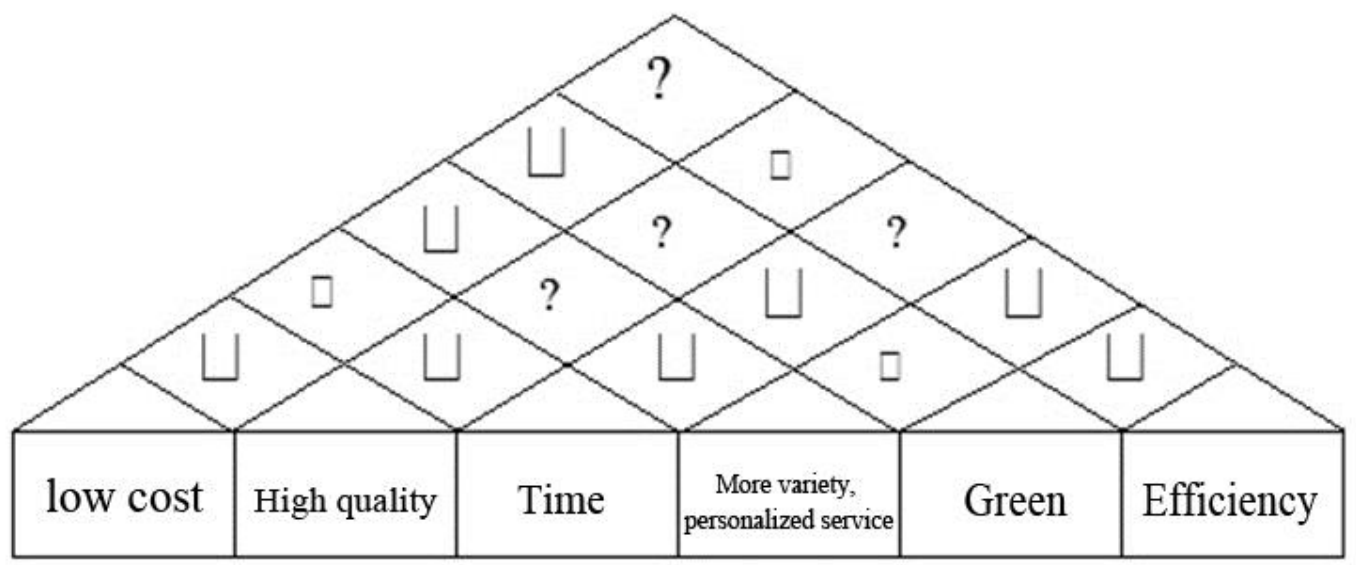

Figure 6. The Autocorrelation Relationship of Enterprise Demand Objective

(5) The determination of competing demands, oriented enterprise established three competitors: A, B, C. While conducting customer satisfaction surveys, and customers evaluate four companies' competitive conditions, Figure 7. By the formula, competitive strength vector $\Phi=(0.086,0.194,0.180,0.075,0.276,0.150)$ 


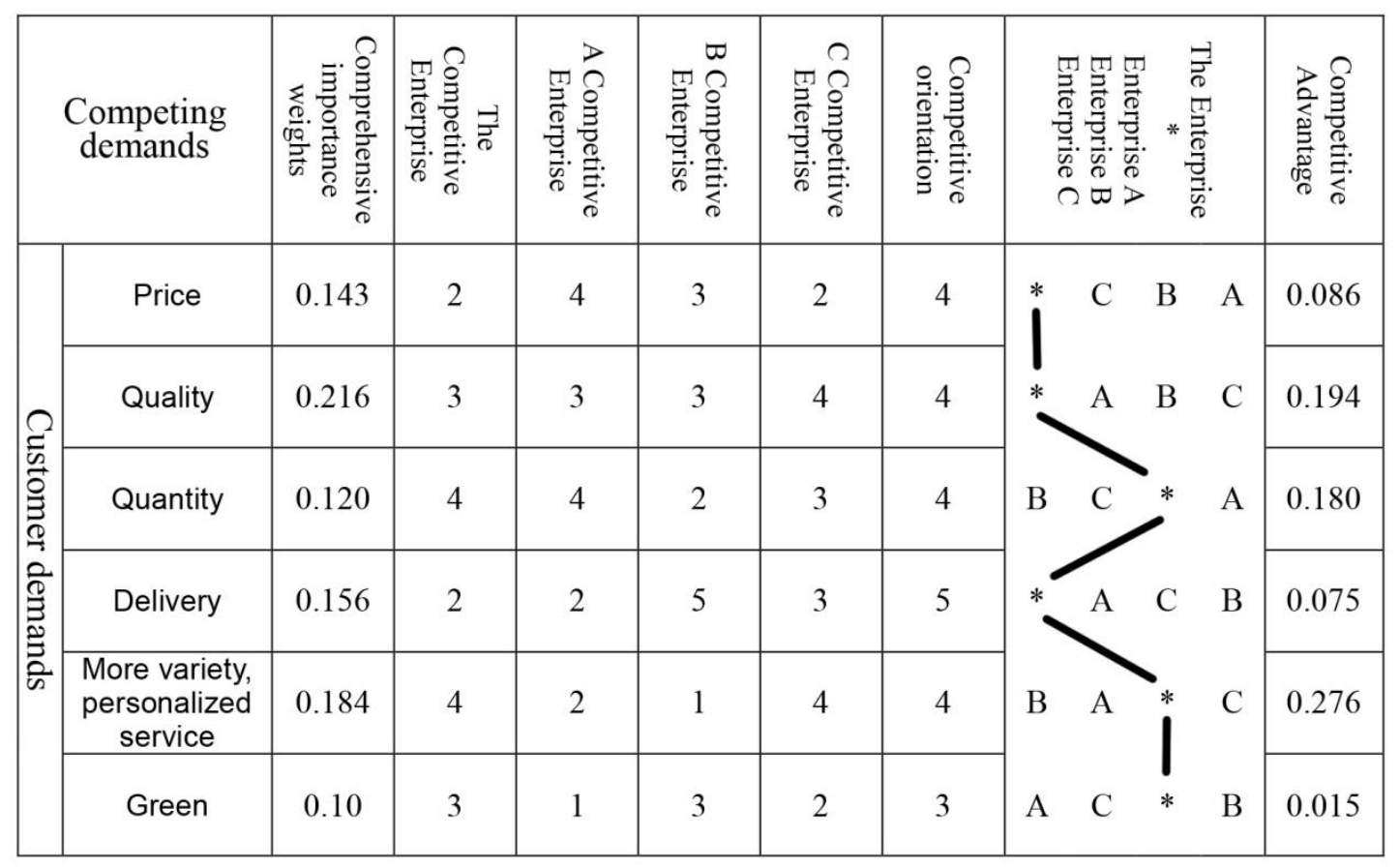

Figure 7. Competitive State

(6) Establish the relationships matrix of customer needs and business demand, the first column fill customer needs; the first line fill the business needs, as shown in Figure 8.

\begin{tabular}{|c|c|c|c|c|c|c|}
\hline $\begin{array}{r}\text { Enterprise } \\
\text { demand }\end{array}$ & $\begin{array}{c}\text { Low } \\
\text { cost } \\
\text { demand }\end{array}$ & $\begin{array}{r}\text { High } \\
\text { quality }\end{array}$ & $\begin{array}{c}\text { Tim } \\
\text { e }\end{array}$ & $\begin{array}{r}\text { More } \\
\text { variety, } \\
\text { personalize } \\
\mathrm{d}\end{array}$ & $\begin{array}{c}\text { Gre } \\
\text { en }\end{array}$ & $\begin{array}{c}\text { Efficie } \\
\text { ncy }\end{array}$ \\
\hline Price & 5 & -5 & 0 & -3 & -3 & -3 \\
\hline Quality & -3 & 5 & -1 & 1 & 1 & -1 \\
\hline Quantity & 0 & -3 & -3 & -3 & -3 & 5 \\
\hline $\begin{array}{c}\text { Delivery } \\
\text { More variety, }\end{array}$ & 0 & -1 & 5 & -3 & -3 & 5 \\
\hline $\begin{array}{c}\text { personalized } \\
\text { service }\end{array}$ & -5 & 3 & -3 & 5 & 3 & -5 \\
\hline Green & -3 & 1 & -1 & 3 & 5 & -1 \\
\hline
\end{tabular}

Figure 8. Relationships Matrix of Customer Needs and Enterprise Demand

(7) The index of relative importance ultimate functional objective is: $\omega=(0.406,0.261$, $0.298,0.436,0.400,0.813$ ) 


$$
\omega_{j(\text { ABSOULtely })}=\eta_{\mathrm{j}} \bullet\left(\sum\left|\mathrm{r}_{\mathrm{ij}}\right| \bullet \phi_{i}\right)
$$

Expressed as the strength vector of competitive advantage, it multiplied mutual importance vector of enterprise needs and customer needs, then the outcome multiplies functional objectives effect coefficient, namely is absolute importance degree of the each functional objectives, so obtained the priority sequence. The final required functional objectives priorities need the absolute important degree normalized: $(0.155,0.100,0.114$, $0.167,0.153,0.311)$

\section{Conclusion}

This paper combined qualitative and quantitative used of QFD method to analysis and solving service-oriented manufacturing system functional objective. It provided scientific and feasibility guidance for actual operating companies. It can be seen from the obtained final calculation of the objective weight of each objective that manufacturers should emphasis on diversification and personalization of products and services and the efficiency of services, etc., However, due to the limitations of QFD method we can only come to focused direction of the objective system functions, and function objective decision is difficult because the complexity of each object and the incommensurability between the various objectives. So it makes functional objective decision is more difficult and it need more in-depth analysis and solutions for various specific objective make decisions.

\section{Acknowledgements}

This research was supported by the LiaoNing Provincial Federation Social Science Circles of China under Grant No. 2015lsljdwt-22, 2015lslktziglx-17, the Soft Science Project No.F13-317-5-29 of Shenyang Science and Technology Bureau, the National Social Science Foundation (project code:15BGL007).

\section{References}

[1] Acquaah M., and Yasai A. M., "Does the implementation of a combination competitive strategy yield incremental performance benefits?" A new perspective from a transition economy in Sub-Saharan Africa. Journal of Business Research, vol. 61 no. 4, (2008), pp. 346-354.

[2] Agus A., and Hassan Z. F., "Enhancing Production Performance and Customer Performance through Total Quality Management (TQM): Strategies for Competitive Advantage," Procedia-Social and Behavioral Sciences, vol. 24 no. 11, (2011), pp. 1650-1662.

[3] Ahn, J. H., Lee S. W., Song, H. J., and Kim H. J., "A survey of architectural features of contemporary object storage systems," Journal of Systems Architecture, vol. 45 no. 5, (1998), pp. 363-386.

[4] Babakus E., Yavas U., and Ashill N. J., "The Role of Customer Orientation as a Moderator of the Job Demand-Burnout-Performance Relationship: A Surface-Level Trait Perspective," Journal of Retailing, vol. 85 no. 4, (2009), pp. 480-492.

[5] Bolloju N., Schneider C., and Sugumaran V., "A knowledge-based system for improving the consistency between object models and use case narratives. Expert Systems with Applications, vol. 39 no. 10, (2012), pp. 9398-9410.

[6] Claver C. E., Pertusa O. E. M., and Molina A. J. F., "Characteristics of organizational structure relating to hybrid competitive strategy: Implications for performance,” Journal of Business Research, vol. 65 no. 7, (2012), pp. 993-1002.

[7] Draman M, Altinel I. K., Bajgoric N., Unal A. T., and Birgoren B., "An Object-Oriented Optimizationbased Software for Agile Manufacturing in Process Industries," Agile Manufacturing: The 21st Century Competitive Strategy, (2001), pp. 265-278.

[8] Gregoriades A., and Karakostas B., "Unifying business objects and system dynamics as a paradigm for developing decision support systems," Decision Support Systems, vol. 37 no. 2, (2004), pp. 307-311.

[9] Hadden J., Tiwari A., Roy R. and Ruta D., "Computer assisted customer churn management: State-ofthe-art and future trends," Computers \& Operations Research, vol. 34 no. 10, (2007), pp. 2902-2917.

[10] Heijltjes M., and Van W. A., "Configurations of market environments, competitive strategies, manufacturing technologies and human resource management policies: A two-industry and two-country analysis of fit," Scandinavian Journal of Management, vol. 19 no. 1, (2003), pp. 31-62. 
[11] Kaiser H. F. (1974), “An index of factorial simplicity. Psychometrika, vol. 39 no. 1, (1975), pp. 31-36.

[12] Kalogeraki V., Melliar-Smith P. M., Moser L. E., and Drougas Y., "Resource management using multiple feedback loops in soft real-time distributed object systems," Journal of Systems and Software, vol. 81 no. 7, (2008), pp. 1144-1162.

[13] Levis A. A., and Papageorgiou L. G., "Customer Demand Forecasting via Support Vector Regression Analysis," Chemical Engineering Research and Design, vol. 83 no. 8, (2005), pp. 1009-1018.

[14] Lockamy III A., and Smith W. I., "A strategic alignment approach for effective business process reengineering: linking strategy, processes and customers for competitive advantage," International Journal of Production Economics, vol. 50 no. 2-3, (1997), pp.141-153.

[15] Ray S. and Jewkes E. M., "Customer lead time management when both demand and price are lead time sensitive," European Journal of Operational Research, vol. 153 no. 3, (2004), pp. 769-781.

[16] Salunke S., Weerawardena J. and McColl-Kennedy J. R., "Towards a model of dynamic capabilities in innovation-based competitive strategy: Insights from project-oriented service firms," Industrial Marketing Management, vol. 40 no. 8, (2011), pp. 1251-1263.

[17] Tegarden D. P., Sheetz S. D., and Monarchi D. E., "A software complexity model of object-oriented systems," Decision Support Systems, vol. 13 no. 4-5, (1995), pp. 241-262.

[18] Tiemessen H. G. H., Fleischmann M., Van Houtum G. J., Van Nunen J. A. E. E. and Pratsini E., "Dynamic demand fulfillment in spare parts networks with multiple customer classes," European Journal of Operational Research, vol. 228 no. 2, (2013), pp. 367-380.

[19] Tsai C. F. and Chen M. Y., "Variable selection by association rules for customer churn prediction of multimedia on demand," Expert Systems with Applications, vol. 37 no. 3, (2010), pp. 2006-2015.

[20] Zäpfel G., "Customer-order-driven production: An economical concept for responding to demand uncertainty?" International Journal of Production Economics, vol. 56 no. 20, (1998), pp. 699-709.

[21] Zhang Y., Zhang W., Xu W., and Li H., "Competitive strategy for on-line leasing of depreciable equipment," Mathematical and Computer Modeling, vol. 54 no. 1-2, (2011), pp. 466-476.

[22] Zhihui Y., Yunqiang Y. and Yizeng C., "Robust Fuzzy Varying Coefficient Regression Analysis with Crisp Inputs and Gaussian Fuzzy Output," Journal of Computing Science and Engineering, vol. 7 no. 4 , (2013), pp. 263-271.

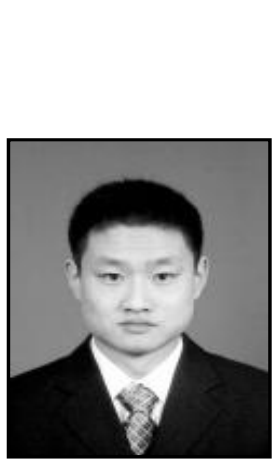

\section{Authors}

Wei Xu, he received the BSc (2003) degree in engineering management from Shenyang University of Technology, the MSc (2006) degree in business management from Shenyang University of Technology. His current research interests include automation systems, manufacturing systems control and numerical control.

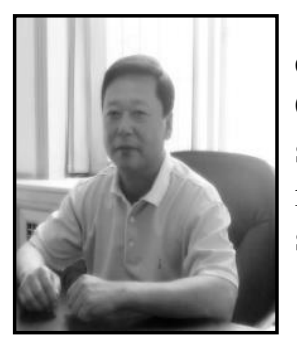

Qingshan Zhang, he obtained his BSc degree in industrial engineering and engineering management from Jilin University, China, in 1982. He then obtained his MSc degree in management science and engineering in 1986. His current research interests include computer-aided process planning, knowledge-based systems and manufacturing systems control.

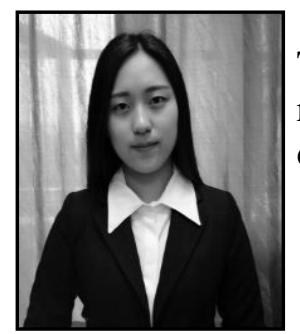

Yue Cao, she is studying at Shenyang University of Technology majoring in engineering management .Her current research interests include the financing of research and development, economics of innovation and new technology. 


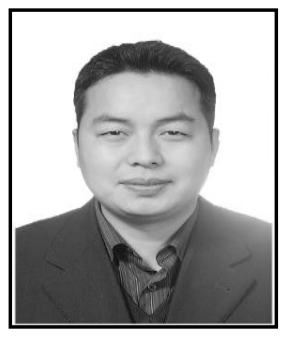

Haijun Wang, he was born in Oct. 1977, and he has worked for enterprises mainly engaged in $\mathrm{R} \& \mathrm{D}$ management for around ten years before he joined Shenyang University of Technology. His research interest is related to enterprise innovation management and product modularity. 
International Journal of Multimedia and Ubiquitous Engineering Vol.10, No.8 (2015) 